\title{
Continuous improvement for the firm's competitiveness: implementation of a new management model
}

\author{
Rabia Azzemou ${ }^{a^{*}}$ and Myriam Noureddine ${ }^{a}$
}

${ }^{a}$ Department of Computer Science, Faculty of Mathematics and Computer Science, University of Science and Technology of Oran "Mohamed Boudiaf" (USTO-MB), Algeria

\section{CHRON I C L E A B S T R A C T}

Article history:

Received: April 26, 2017

Received in revised format: September 26, 2017

Accepted: November 15, 2017

Available online:

November 16, 2017

Keywords:

Process of production

Performance

Competitiveness

Continuous improvement

Lean Manufacturing

\begin{abstract}
To get ready for the hard international competition, firms have to convince themselves of the pressing necessity of optimizing its competitiveness factors. In this perspective, this article proposes a general model of management system of firms through the implementation of tools of Lean Manufacturing. This method establishes an approach to introduce an action plan to improve the performance of a firm. Knowing that the Algerian firms do not escape the constraints of competitiveness, the adopted model is applied to two strategic firms of the Algerian industry and the final result gives a series of measures to improve their competitiveness and their performances, simultaneously.
\end{abstract}

\section{Introduction}

Any firm is subjected to a phase of major transformations the objective of which is situated in the research for an improvement of the performance. The improvement of the system of production and the productivity conditions practically the survival of companies and this improvement aims at returning the more competitive company to face the threats and to meet the challenges with which it is confronted today. This paper proposes an environment of continuous improvement, based on the integration of the tools of Lean Manufacturing which is a continuous improvement approach concentrated towards the reduction of the wasting, focusing to achieve zero waste concept (Chahal \& Narwal, 2017), for a production and a more just efficiency. Indeed, at present Lean Manufacturing establishes a competitive method to analyze the dysfunctions of the company and set up an action plan to improve its performance. We propose a set of solutions for strengthening the competitiveness of the organization. Considering the internal and external constraints which have to face the Algerian company, the research for the improvement and for the efficiency of companies is difficult. In spite of the measures taken by public authorities we observe an importing gap between the shown intentions and the results obtained

* Corresponding author

E-mail address: rabiazzemou@gmail.com (R. Azzemou) 
on the ground. This reserved report of the device exhorts the Algerian company to think again about a new approach to reach a renewal of dynamism by which the objective is left the competitiveness. Even on its own internal market, the Algerian company is confronted every day with a more and more rough competition and also with imperatives of performance. She inevitably has to adapt itself, evolve and improve to answer her fundamental objectives of deadlines, costs and quality. In this context, the proposed environment is applied to Algerian companies and the result shows the improvement of the productivity of companies concerned through the proposal of a series of measures to improve at the same time the competitiveness and the performances of this company.

We present in the second section the concepts bound to the competitiveness of the company. The third section concerns the proposed model of improvement. The application of the model on real companies is exposed in the fourth section and the final result gives a series of measures to improve at the same time the competitiveness and the performances of these companies.

\section{The firm and the competitiveness}

\subsection{The competitiveness}

Competitiveness has become a fundamental preoccupation in the modern economy for both the developed and the emerging countries. Indeed, the prosperity of a country depends on its competitiveness which leans on the productivity of its firms. Despite the fact that no one can deny its importance, the interpretation of the concept of competitiveness remains, somehow, ambiguous (Bellon, 1991; Kotler \& Dubois, 2006; Porter, 1998). To elucidate this ambiguity, it is necessary to specify some entities such as, state economy, sector, company, product and service. Certainly there are systematic links between these various concepts. Indeed, we cannot speak about a competitive economy only through a competitive sector, a competitive firm and a competitive product. A non-competitive product results from a non-competitive firm and engenders a non-competitive sector (Azouaou, 2010). Competitiveness corresponds to the capacity with which a firm, to some extent, has to resist its competitors. It is often confused/ mixed with its financial translation, profitability or productivity. Profitability and productivity are only partial measures of competitiveness which is characterized by an advantage with regard to the competitors on the market. The Organization for Economic Co-operation and Development (OECD) defines competitiveness as being the latitude which has a country evolving in conditions of a free and fair market to produce the goods and the services which satisfy the international standards of the market while maintaining and simultaneously increasing the real income of its inhabitants in the long term. This is a macroeconomic definition, while competitiveness is initially a firm concept transposed to a macroeconomic scale (Berger, 2008). Competitiveness supposes the existence of an organized economy market where competitors freely offer their goods and services. Rivalry, undertaking capacity and freedom for price controls are the three necessary conditions to give birth to competitiveness.

\subsection{Competitiveness Factors}

The firm possesses several factors of competitiveness classified according to two types: price competitiveness factors and non-price competitiveness factors (Dejardin, 2006).

- The non-price competitiveness

Independently of the competitiveness at the level of the price of the product, the firm can resort to other factors of competition, as:

- The quality: the quality of products is an important factor of competitiveness.

- The brand image of the firm: the brand image of the firm confers her latitude to sell its products more expensive than those of her competitors who can even present certain superior qualitative aspects. 
- The services to the customers: at price and quality more or less equal, certain firms direct their commercial policy on the quality of the service provided to their clientele.

- The technological innovation: a product always incorporating a technological novelty will have a competitive advantage on the products of the competitors.

- The differentiation of the product: it is a shape of customization of the product by trying to satisfy with more precision the needs for every category of clientele.

- The factors of competitiveness-price

The price is one of fundamental factors of competitiveness for the firm. Indeed, the firm fetches to sell its property to the possible lowest price (excepted in the sector of the luxury), to be able to gain customers and thus market shares. To be able to lower the price and obtain a competitive price, the firm has three solutions:

- Reduce its production costs: the firm which succeeds in lowering its production costs can reduce its sale price.

- Reduce its commercial margins: the firm can reduce its sales margin to sell its products to the cheapest possible price of the market.

- Take advantage of differences of exchange: the firm which exports can take advantage of differences of exchange which exist between its national currency and that of the country in which it sells its products.

\subsection{Analysis of the competitiveness:}

The competitiveness of a firm is analyzed through the degree of flexibility of its structure (Lawrence \& Lorsch, 1989). For a firm to be competitive, its structure has to be in compliance with the requirements of its environment. In other words, if the environment changes the structure of the firm, it must adapt to that.

Competitiveness is based on three fundamentals:

- The basis of the firm competitiveness: through the firm structure observation (a state of structure made of key points and weak points).

- The capacity of ruling the firm: through the observation of the skill level of the leaders.

- The competitive insertion: observation of the firm's situation with regards to its environment.

The firm competitiveness is visible only within an established environment by competitors operating in the same sector. By comparing itself to firms of the same space, through competition, one perceives the relative importance of the acquired advance or delay.

Today, the current competitiveness conditions are not characterized by the market globalization of the actors increase, but by the technological changes including logistic excellence such as Lean Manufacturing.

\subsection{Tools of Lean Manufacturing}

Lean Manufacturing aims at optimizing all the processes of the firm, at eliminating the wasting from it and at implementing a light, agile and effective organization. Lean is interested in the performance that is the productivity and the quality (Kumari et al., 2015). An organizational shape adapted to a world, global and quickly evolutionary environment while consisting in eliminating the activities which do not contribute to the value creation for the stakeholders (more specially the customers) so as to concentrate the resources on the critical processes. The study led in forty (40) companies highlighted an average increase of the $50 \%$ productivity and an average reduction of the $80 \%$ stocks (Kilpatrick, 2003). Profits were observed as long in large companies that in small and medium-sized enterprises (Shah \& Ward, 2003; Demeter \& Matyusz, 2010), as well as in numerous business sectors to the services (Lyonnet, 2010). Lean Manufacturing can offer promising perspectives regarding competitiveness to the firm 
because he does not suggest starting all over again, but leaning on the existing and acting on the ground. It is an approach which starts some approval to go back up towards the upstream from tools and from common sense having for objective the strengthening of the competitiveness of the organization.

The implementation of the approach Lean and its tools allows to increase the performance by answering customer expectations while eliminating the useless costs throughout the value chain (reduce the deadlines of manufacturing; eliminate overstocks, to optimize the surfaces of production and to treat all the quality causes produced). It results from it a financial gain important for the firm by the improvement of the methods of work.

Based on the participative management and the implementation of a dialogue of performance within the teams, this approach allows to identify the dysfunctions and to result in tracks of actions to improve its performance.

Lean Manufacturing includes several tools which apply to all the environments and facilitate the actions of transformation of the firm.

Some of these tools are (Chahal \& Narwal, 2017; Kumari et al., 2015):

- 5S: the basic rules for order and discipline, they are inevitable preliminaries for any project of improvement,

- Visual management: a steering base for a continuous improvement of everyday life which objective is to inform in real time and allow an immediate reaction to solving problems,

- Kanban: a production organization system with maps or via a simple visual system allowing to view the flows and to reduce important inventory and stocks,

- Poka Yoke: a simple system allowing to avoid operators involuntary errors and is called" anti-error system ",

- SMED: a Single Minute Exchange Die. The Deepening of value-added optimization time: an organization method to optimize an unproductive functioning situation to gain in flexibility,

- Value Stream Mapping (VSM): a method of analysis which allows defining the main productivity reserve of a production unit by tracing the complete room production flow. The flow of parts measured time, stock levels and their value, allows defining a certain number of improvement construction sites to be set up first and foremost in a Lean Manufacturing approach.

- Total Productive Maintenance (TPM): it is an essential Lean Manufacturing tool that measures breakdowns and machine stops as well as their associated risks. A corrective action plan can be set up then, as well as a real preventive maintenance management.

\section{Continuous improvement model proposed}

The improvement of the system of production and the productivity conditions practically the survival of firms. To master an effective production, it is necessary to eliminate the useless activities, to handle all the causes of delay by accelerating all the activities, to fight against the wasting, have qualified personnel capable of developing a realistic plan and of a reliable information system (Marty, 1997). It led firms to turn to Lean which turns out to be an interesting way to improve the performance of the long-term firms (Real et al., 2007).

The objective of our search is to contribute to the improvement of the competitiveness of firms by proposing them the implementation of the approach Lean. So, it is a question of applying this approach to set up certain tools adapted to the specificities of firms.

It thus becomes essential to try to include how companies can improve their chance of survival and/or growth by the use of tools and concepts of management used by the most successful firms.

\subsection{Application environment.}

The environment of application proposed in Fig.1 is based on the integration of Lean tools, having for objective to propose a set of solutions for the strengthening of the competitiveness. 
- Implied tools

For the implementation of our approach we opted for three tools training a general framework of analysis which allows arresting the management system of the firm in a more and more competitive context where the performance is not only translated any more in terms of financial efficiency. These three tools, the diagram of Ishikawa, the 5S and the VSM, are involved in the dynamics of the change and in its conduct. They contribute to the continuous improvement at every level. Our choice for these tools is justified at the same time by the simplicity of their use and their importance in any approach Lean integrating an elimination of the dysfunctions, in a concern of improvement of the productivity.

\section{- Diagram of Ishikawa}

The first one, the diagram of Ishikawa to highlight compartments roots of the problem. The diagram of Ishikawa (Ishikawa, 1990; 2007) or diagram $5 \mathrm{M}$ stays one of the tools quality the most known and most used. It is the graphic tool which serves to understand the causes of a quality defect and to analyze the relationship existing between a problem and all the possible causes. The causes which can be at the origin of a problem are classified according to five families: People, Environment, Methods, Machines, and Materials. Every family of cause receives other causes according to the level of importance or detail. It is an excellent communications tool to explain a phenomenon.

\section{- Tool 5S}

The second, the $5 \mathrm{~S}$ is a tool which allows eliminating the time lost to look for its tools, to improve the safety and the efficiency, to decrease and prevent the breakdowns, to release from the space pointlessly used.

The 5S (Seiri, Seiton, Seiso, Seiketsu and Shitsuke) is the first tool to be implemented in an approach of type Lean Manufacturing. The 5S (Jaca et al., 2014) allows to eliminate what is useless, to define a place or everything, to clean, to define the ranges and the necessary procedures finally to audit and to measure the improvement. She allows a better environmental monitoring on the ground (Imai, 1997). It also establishes a way to set up a participative management by giving responsibilities the operators on the organization of the firm (Trey, 2003). This basic tool of Lean has for main objective to change the mentalities and to start a politics of continuous improvement. The application of 5S allows building robust foundations of an approach Lean Manufacturing (Gupta \& Jain, 2013).

\section{- Value Stream Mapping (VSM)}

The third tool the VSM is the way simple and understandable for the entire staff which allows to describe, to map all the flows (physical, informative, organizational) which characterize a process. Value Stream Mapping (VSM) is also known under the name of Material and information Flow Mapping or Material and information Flow Analysis: MIFA, or analysis of the chain of the value. The VSM is a tool to register a current state (Mapping) and conceive a future state (Design) of the flows of material and information at the global level. This method of analysis of Lean Manufacturing allows defining the main reserves of productivity of a production unit by following the complete flow of the production of a part. It is a question of displaying the flow of creation of the value along a process, of identifying it that is to collect the information relative to the diverse stages (Sigh \& Sharma, 2009). Indeed, a flow browses successive tasks of a starting point up to its place of destination and the concept Toyota (Sigh \& Sharma, 2009) identified three types of flows handled by the VSM: physical flow of the materials, flow of information and flow of the people / process. The main objective is to set up a politics of continuous improvement because the mapping is only the first stage of the reorganization of the production line. 
These three tools of Lean are different but complementary. They work all at the same objective to know the elimination of the wasting.

- Architecture of the model

The proposed model in Fig. 1 can be adaptable as well to the firms of production as to the firms of services. This model consists of a continuous improvement approach which includes a fundamental stage of identification of the dysfunctions, which is going to allow releasing the tracks of improvement, which must be implemented by the administrators.

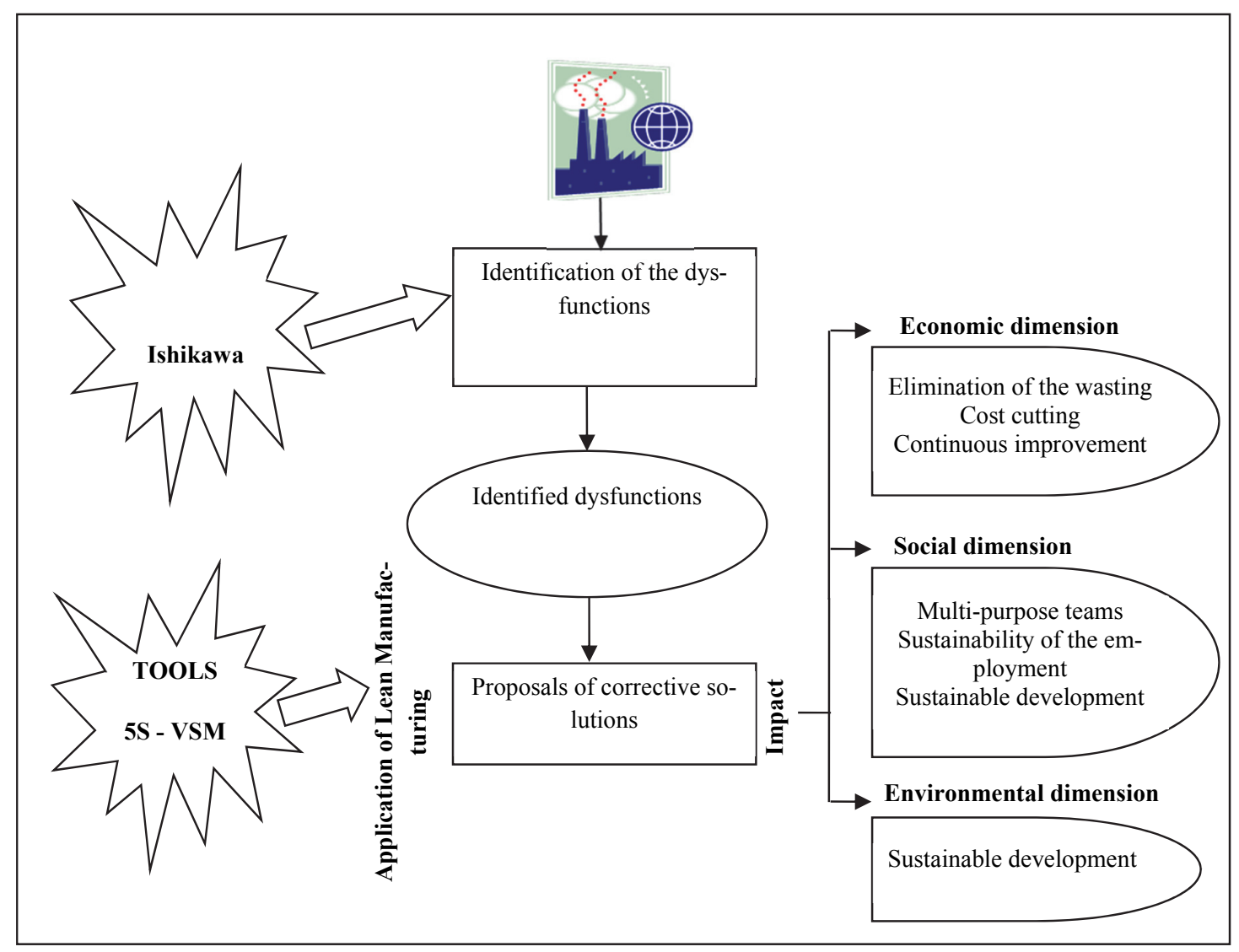

Fig. 1. Architecture of the proposed model for continuous improvement

\subsection{Approach of proposed continuous improvement}

The proposed approach contains two sequential and iterative stages.

The first stage occurring upstream to the approach takes as starting point the identification of the dysfunctions by means of the Ishikawa diagram. The latter is used to look for the causes of a dysfunction in the production and it is made to be very visual serving as support on second thought of group.

The second stage consists of the integration of the Lean Manufacturing tools in the environment to propose solutions according to three approaches: economic, social and environmental.

In this stage, we opted for the tools, VSM and 5S, used respectively in the following two sub steps.

- Sub step of diagnosis

A diagnosis is realized at first by means of the VSM. This method aims at analyzing the flows of material, the flows of information and the organizational flows about the whole process of production, 
since the command of the customer until the delivery of the product or the service. It is a question of spotting the wasting, the wastes of time and the bottlenecks. So the analysis of the flows of value creation thanks to this tool will highlight the tracks of progress and gain. During this diagnosis, the difficulties and the sources of wasting are identified for every stage of the process.

- Sub step of correction

On the basis of the stage of diagnosis, a construction site is identified and prioritized to reduce the wasting; we propose the construction site $5 \mathrm{~S}$ which is a powerful tool in the service of a winning marketing and a powerful tool of cost cutting. It is a question of estimating the management system and its operational practices at the fault this tool.

\section{Application to the Algerian firms}

The adopted approach is implemented on two strategic firms following both sequential stages: identification of the dysfunctions by means of the diagram of Ishikawa in the system of production and then application of tools 5S and VSM.

\subsection{Public firm}

The first chosen firm is an important firm within the Algerian industry because it is a complex (Azzemou \& Noureddine, 2012) that has for main objective the liquefaction of the natural gas with the capacity of extraction of the propane, the butane and the gasoline.

- Specification

The complex is established of three (03) essential and different zones:

- Zone of the utilities: production of the electrical energy, the vapor, the desalinated water, the nitrogen and the water of cooling.

- Zone of processes: this zone consists essentially of identical liquefaction trains.

- Zone of storage and load: this zone has for role the storage of the Liquefied natural gas (GNL) and the gasoline in specific tubs as well as load of these products towards.

The company of the complex gasman contains identical trains of manufacturing which work in parallel. Their functioning requires having a source of energy: the vapor as the main source and the produced electricity it even by the vapor. The boiler being the mechanism which produces this vapor knows recurring breakdowns. To correct these distortions, it is necessary to make so that the breakdowns do not occur any more.

According to the adopted methodology, we identify all the dysfunctions to discover the origin of the incidents by means of the diagram of Ishikawa. Then, we apply the $5 \mathrm{~S}$ to allow a better environmental monitoring on the ground. Finally, we shall make a precise current situation by means of the VSM then it analyze and establish a future situation. At the end of these applications, we propose the implementation of corrective actions for the listed dysfunctions.

- Application of the approach

The problem posed is the recurring breakdowns of the producing boiler of the vapor which feeds trains. The objective is to avoid the ruling of machines and thus the interruption of the production as well as the prolonged ruling of the boiler which is going to urge the latter to work on full responsibility "pushed step" to catch up the lack of production. The dysfunctions are included in the fish bones of the Ishikawa 
diagram, by considering respectively 5M: methods, peoples, Raw materials for the information, Means for machines and Environment.

After that, we applied the 5S method to the obtained dysfunctions with proposals of future actions to be led (Azzemou \& Noureddine, 2012), for improving the productivity and the performance of the system.

In this context and among the axes of the Ishikawa diagram, we consider the particularly both cases "Methods" and "Raw materials" for the application of 5S (Table 1).

For the axis "Methods": the lack of coordination between the services arouses the haste in the decision-making. Indeed, the absence of the working procedures causes a failure in the maintenance and a deficiency in the periodic control. The application of the tool 5S through S2 (to tidy up), the S4 (order) and S5 (rigor) is going to help in the improvement of the set up information system.

For the axis "Raw materials": the bad combustion due to the excess of quantity of gas entrained an excess of vapor so generating a loss of electricity. Runner of the principle that losses are potential profits, to eliminate the losses constitutes a gain for the firm. In this case, the deployment of the tool $5 \mathrm{~S}$ through $\mathrm{S} 1$ (sort out and throw), S2 (tidy up), S3 (clean) and the S4 (order) is going to participate to improve the flows of the information system.

Table 1

Application of the $5 \mathrm{~S}$ on the identified dysfunctions (1st firm)

\begin{tabular}{|c|c|c|c|c|c|c|c|}
\hline \multirow{2}{*}{$\begin{array}{l}\text { Ishikawa } \\
\text { axis }\end{array}$} & \multirow{2}{*}{ Dysfunctions } & \multicolumn{5}{|c|}{ 5S Tool } & \multirow{2}{*}{ Corrective actions } \\
\hline & & 1 & 2 & 3 & 4 & 5 & \\
\hline \multirow{6}{*}{$\begin{array}{l}\frac{n}{0} \\
\frac{1}{ \pm} \\
\sum_{2}^{e}\end{array}$} & Defective and unimplemented maintenance & & $\sqrt{ }$ & & $\sqrt{ }$ & $\sqrt{ }$ & \multirow{6}{*}{$\begin{array}{l}\text { Set up procedures to im- } \\
\text { prove the information } \\
\text { system }\end{array}$} \\
\hline & Haste in the decision-making & & $\sqrt{ }$ & & $\sqrt{ }$ & $\sqrt{ }$ & \\
\hline & Deficiency in the periodic control & & $\sqrt{ }$ & & $\sqrt{ }$ & $\sqrt{ }$ & \\
\hline & $\begin{array}{l}\text { Databases instrumentation process incom- } \\
\text { plete }\end{array}$ & & $\sqrt{ }$ & & $\sqrt{ }$ & $\sqrt{ }$ & \\
\hline & Non-existence of working procedures & & & $\sqrt{ }$ & $\sqrt{ }$ & $\sqrt{ }$ & \\
\hline & No coordination between the services & & & $\sqrt{ }$ & $\sqrt{ }$ & $\sqrt{ }$ & \\
\hline \multirow{4}{*}{ 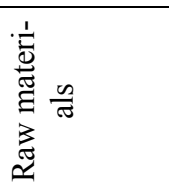 } & Excess of quantity of gas & $\sqrt{ }$ & $\sqrt{ }$ & $\sqrt{ }$ & $\sqrt{ }$ & & \multirow{4}{*}{$\begin{array}{l}\text { Information system To } \\
\text { keep the necessity; elimi- } \\
\text { nate the useless }\end{array}$} \\
\hline & Bad combustion & $\sqrt{ }$ & $\sqrt{ }$ & $\sqrt{ }$ & $\sqrt{ }$ & & \\
\hline & Excess of vapor & $\sqrt{ }$ & $\sqrt{ }$ & $\sqrt{ }$ & $\sqrt{ }$ & & \\
\hline & Loss of electricity & $\sqrt{ }$ & $\sqrt{ }$ & $\sqrt{ }$ & $\sqrt{ }$ & & \\
\hline
\end{tabular}

We propose as action a better management of the information system. The firm has an information system and a plan of production adequate to its strategy. However, he was noticed by the dysfunctions at the level of the system of production. To act, we propose a complementary information system to the existing system.

It will allow the administrators:

- To anticipate the problems this can appear,

- To check the execution of the processes to improve the life expectancy of equipment,

- To eliminate the dysfunctions which allow decreasing the productivity and the quality of products,

- To facilitate the information sharing between the various departments (supplies, technique, maintenance),

- To prepare periodic forecast of supply in replacement part, equipment, etc,

- To facilitate the work and the planning of the maintenance department.

In this context Value Stream Mapping (VSM), tool of Lean Manufacturing allows a descriptive mapping of flows and allows all the actors of the firm to participate, to understand and to share. 
Resting on the existing, we have in the first phase of our approach, followed the various flows. We so spotted four (4) wasting grouped according to 2 cases. After analysis, we identified their causes in the production process (Table 2 ).

\section{Table 2}

Wasting and causes

\begin{tabular}{ccc}
\hline Case & Wasting & Causes \\
\hline Overproduction & $\begin{array}{c}\text { Excess of production or load } \\
\text { Accumulation of stock and outstanding } \\
\text { discounted bills }\end{array}$ & $\begin{array}{c}\text { Irregular load of ships due to the bad weather } \\
\text { Stock }>=270000 \mathrm{~m} 3 \text { at the level of tubs }\end{array}$ \\
\hline $\begin{array}{c}\text { Useless } \\
\text { transport }\end{array}$ & Useless operations & $\begin{array}{c}\text { Transport, dismantling of the pumps of train towards } \\
\text { workshops }\end{array}$ \\
& Inoccupation of machines or people & Lack of parts delays maintenance works and causes the \\
stop of trains.
\end{tabular}

For identification of the dysfunctions of the process of production of the established company, it is necessary to translate this diagnosis in the form of objectives aiming at the improvement of the process. It is a question of setting up the actions of optimization which will lead to modify in a stronger way the process. A simulation of the flows of production over a period of four months allowed verifying daily the flows of information emanating from various posts, to consult daily reports to watch the continuity of the production and to guarantee the coherence of the data. So, the position of trains is in working order is in a state of ruling can be quickly indicated, what will allow to throw corrective actions. Then, it is a question of reshaping the various flows to imagine and establish a future more effective, reactive, less expensive and more coordinated state. According to the various types of wasting, we consider 2 cases of overproduction and useless transport.

\section{Case of overproduction}

In the first situation of overproduction in Fig.2, the firm is confronted with an accumulation of stock which is translated by a stock upper to $270000 \mathrm{~m}^{3}$ at the level of tubs (ferries, high school diplomas), an excess of production when a train breaks down or by bad of time (current State). To remedy these dysfunctions, we propose as corrective and preventive action the implementation of a complementary information system to the existing information system (future State). The implementation of this system is going to contribute to regulate on one hand flows thanks to the alert to stop the production and on the other hand indicate number of train out of order.

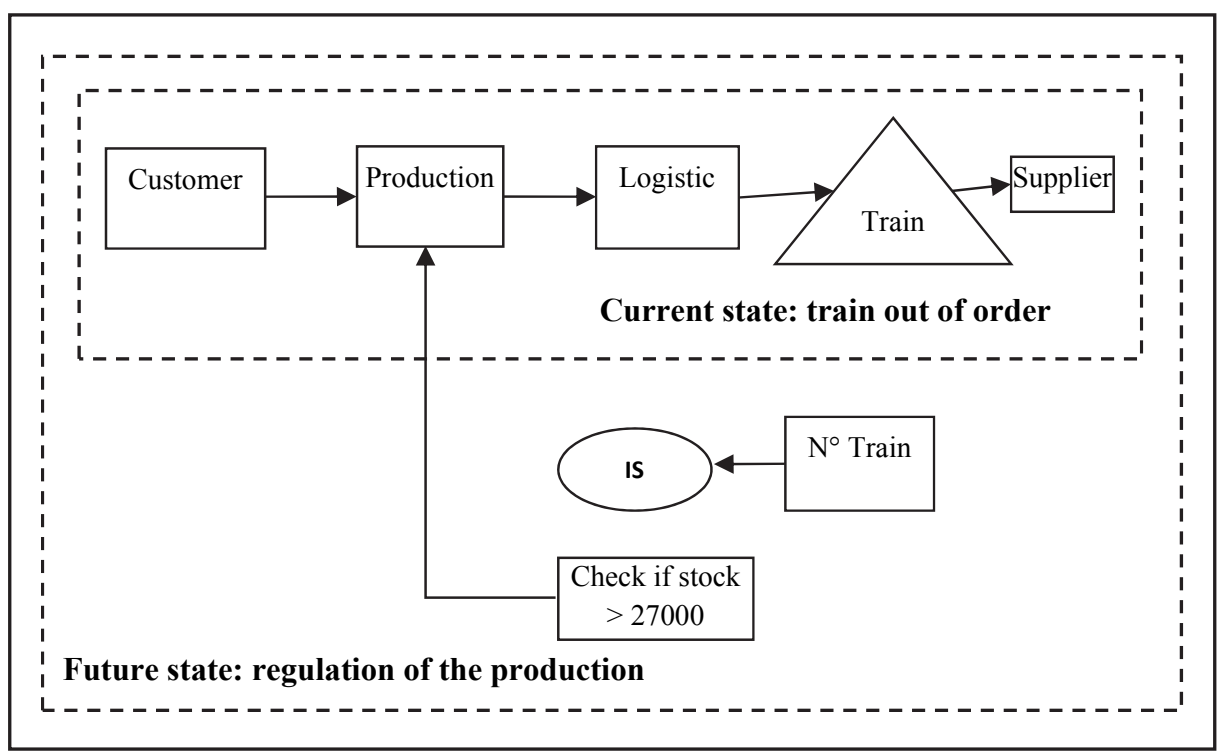

Fig. 2. Cost reduction of storage by avoiding an overproduction 


\section{Case of useless transport}

In the second situation of useless transport in Fig.3, we notice movements and useless movements which create no added value. Indeed, when a train breaks down, we defuse the defective part and we transport it at the level of the workshop. After repair, the part returned and went back up on the train. What is translated by two round trips (current State) between the train and the workshop so increasing a hardness of the work and the consumption of the space? Our proposition consists in the implementation of one if which is going to allow to give all the information concerning the types of breakdowns, concerning the spare parts and concerning the numbers of train out of order. So, it will reduce the number of travels to a travel made about is the number of breakdowns (future State). It is going to contribute to reduce unproductiveness added generated by the useless travels and to increase the productivity.

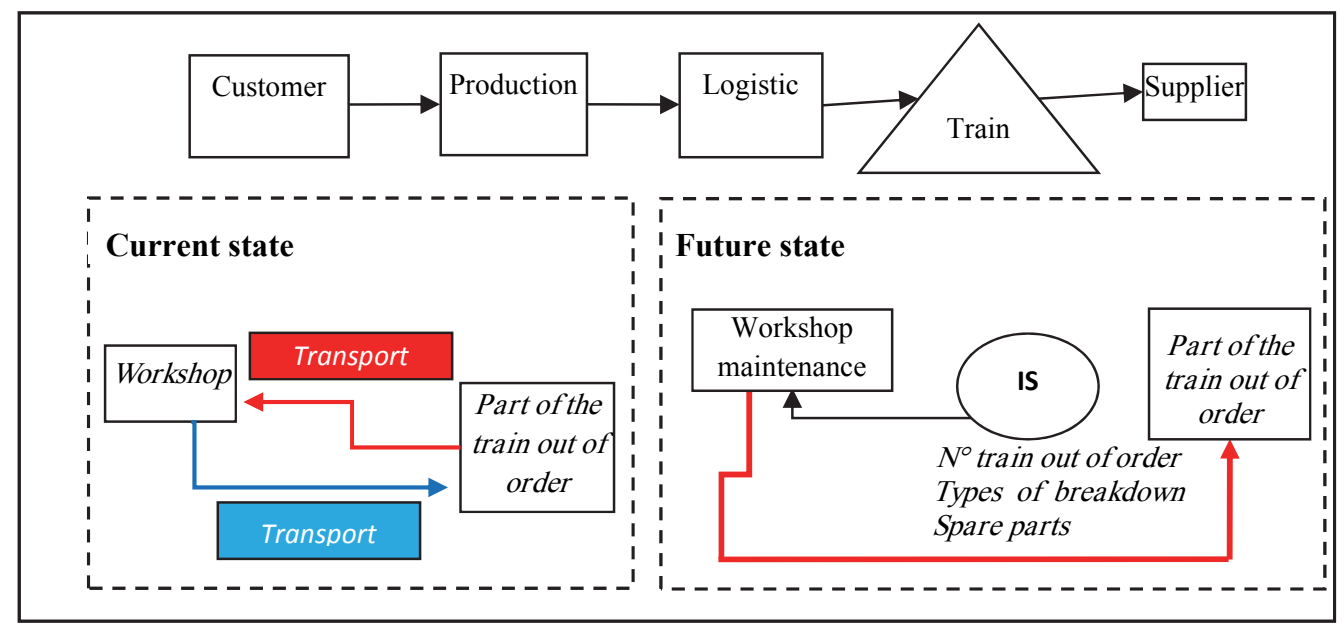

Fig. 3. Reduction of useless transport

The organization bases essentially on the informative flows which can be interrupted for numerous technical, human, natural reasons, etc.; therefore, the major stake is to avoid the break of the chain and to favor the continuity of flows. In this context, it is necessary to take into account the following parameters:

- The duration of car park of the train before load to be able to find other one of the train of replacement,

- The frequency of filling of tanks,

- The limitation of the production according to the available capacity of tanks.

\subsection{Private enterprise}

The second chosen firm is a private enterprise classified as a small and medium-sized enterprise (SME) within the Algerian industry.

- Specification

The concerned Algerian small and medium-sized enterprise (SME) counts about sixty employees, it makes and markets products (Azzemou \& Noureddine, 2014) in stainless steel (flatware, cutlery industry, stainless steel kitchen utensils and aluminum, work tables and bakery, shelves, stalls of butcher's shop, dishwashing and stainless steel kitchen sinks, stainless steel isothermal safes, robotics and material wagons, equipment of bakery, equipment for community and restoring, etc.). Her customers are essentially communities, companies, hospitals, army, etc. through all the regions of Algeria.

This SME makes two types of products:

- A standard product (uniform and continuous manufacturing): available Product (completely or partially) at the level of the store. This type of already marketed product is conceived and realized from an already existing prototype; 
- A specific product: unavailable Product at the level of the factory. He can be completely new and passes by the prototype of the product from activities of conception and feasibility study.

- Application of the approach

This SME tries to develop and to undertake in ISO certification 9001. However, she is confronted with difficulties of organizational order. The management of the space establishes the weak point in the management of the workshop. Indeed, it increases the travels of the workers and consequently produces a negative effect on the production. In this context, we propose the setting-up of the KAIZEN activities (Imai, 1997) by adopting the tools of Lean Manufacturing at the level of the workshop. It is going to need to rethink the reorganization of the space and the methods of work according to three axes: technique ("to Fit out and to Indicate" to fluidity and regulate the circulation), human being ("to see to be seen" and to circulate in safety) and organizational ("to organize and to formalize" to optimize the production and secure the work). The description of the manufacturing process (Azzemou \& Noureddine, 2014) by the diagram this below is going to allow displaying the sequences of the operations in Fig.4. For the manufacturing of a product, the successive stages show the chain of the operations representing the flows of the material and the travels of the workers.

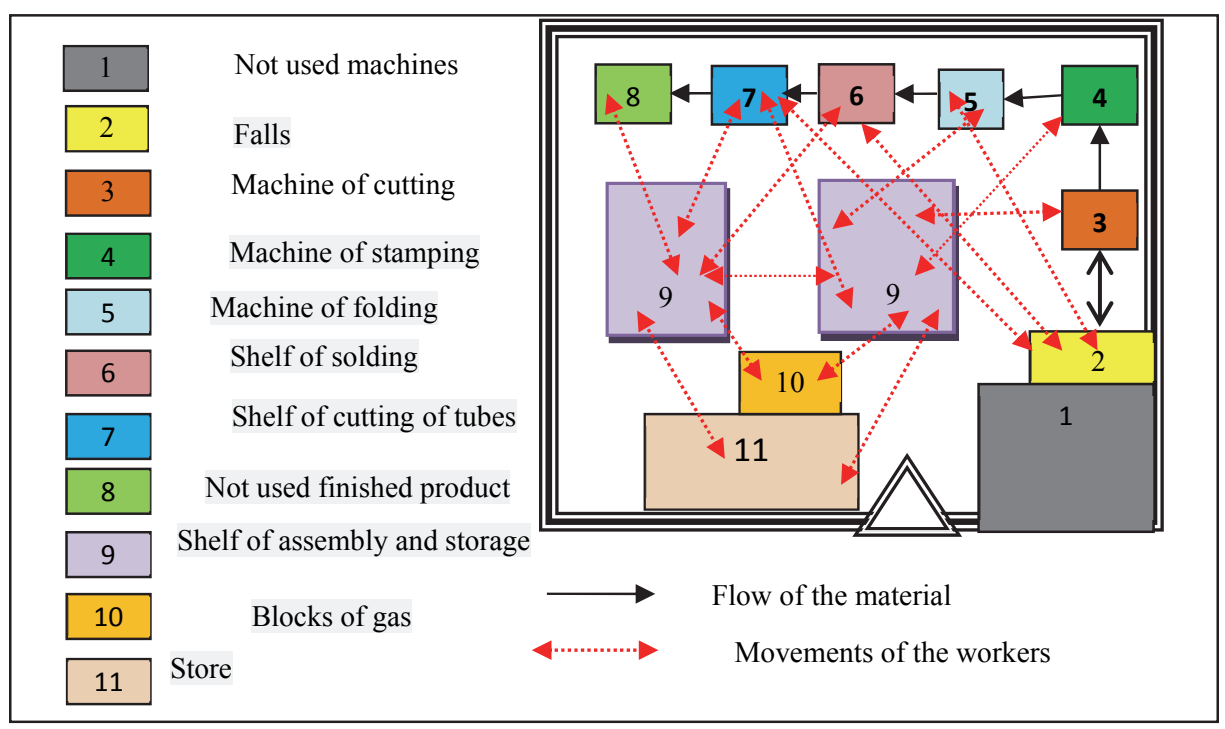

Fig. 4. Organization of the workshop

The objective is to assure the productivity by optimizing the organization of the factory, by reducing the times of manufacturing and by improving the quality of the products of this firm. During the period of observation, the problem posed is the improvement of the efficiency of the work. The found dysfunctions are grouped in the fish bones of the diagram of Ishikawa. Having found the dysfunctions by means of the diagram of Ishikawa, we apply the method $5 \mathrm{~S}$ to these dysfunctions, by proposing corrective actions which the company could lead to improve her organization. According to Joseph Juran, $80 \%$ of the dysfunctions in a company are attributable to the organization (Juran, 2004). The company is confronted so with diverse organizational problems. Among the axes of the diagram of Ishikawa and according to the identified dysfunctions, we are interested in three axes "Methods", "People" and "Environment" to apply it 5S (Table 3).

$>$ For the axis "People (manpower)": the failing communication arouses inattention of the workers. It also engenders useless movements causing fatigue and stress and consequently a lack of efficiency. The introduction of a multi-purpose agent (water spider) is going to allow facilitating the tasks to the whole team of the workshop.

$>$ For the axis "Environment" ("Middle"): the blocked job entrained a binding handling. In this case, the deployment of the tool 5S through S1 (sort out and throw), S2 (tidy up), S3 (clean) and the S4 (order) is going to participate to improve the circulation of the physical and informative flows. 
For the axis "Methods": the failing maintenance and the bad organization of the arrangement of tools entrain an increase of the maintenance cost and risk raising the security problems. The application of the tool 5S through S1 (sort out and throw), S2 (tidy up), S3 (clean), the S4 (order) and S5 (rigor) is going to help in the improvement of the best practices of efficiency in jobs and in the improvement of the set up information system.

Table 3

Application of the 5S on the identified dysfunctions (2nd firm)

\begin{tabular}{|c|c|c|c|c|c|c|c|}
\hline \multirow{2}{*}{$\begin{array}{l}\text { Axes Ishi- } \\
\text { kawa }\end{array}$} & \multirow{2}{*}{ Dysfunctions } & \multicolumn{5}{|c|}{ 5S Tools } & \multirow{2}{*}{ Corrective actions } \\
\hline & & 1 & 2 & 3 & 4 & 5 & \\
\hline \multirow{6}{*}{$\frac{0}{\tilde{D}^{2}}$} & Put under stress and tired staff & & & & $\sqrt{ }$ & $\sqrt{ }$ & \multirow{6}{*}{$\begin{array}{l}\text { Improve the working conditions } \\
\text { Adapt the internal communication } \\
\text { Identify flows with arrows with the ground or } \\
\text { on walls }\end{array}$} \\
\hline & Useless movements & $\sqrt{ }$ & $\sqrt{ }$ & $\sqrt{ }$ & & & \\
\hline & Inattention & & & & $\sqrt{ }$ & $\sqrt{ }$ & \\
\hline & Be lacking efficiency & & & & $\sqrt{ }$ & $\sqrt{ }$ & \\
\hline & Failing communication & & & & $\sqrt{ }$ & $\sqrt{ }$ & \\
\hline & Bad manipulation & & & & $\sqrt{ }$ & $\sqrt{ }$ & \\
\hline \multirow{5}{*}{ 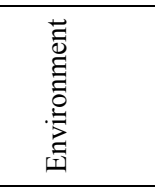 } & Space of storage reduces & $\sqrt{ }$ & $\sqrt{ }$ & $\sqrt{ }$ & & & \multirow{5}{*}{$\begin{array}{l}\text { Improvement of the working conditions } \\
\text { Reorganization of the factory } \\
\text { Make a reorganization of paths, entrances, ex- } \\
\text { its }\end{array}$} \\
\hline & Binding handling & $\sqrt{ }$ & $\sqrt{ }$ & $\sqrt{ }$ & & & \\
\hline & High sound level & & & & $\sqrt{ }$ & $\sqrt{ }$ & \\
\hline & Blocked job & $\sqrt{ }$ & $\sqrt{ }$ & $\sqrt{ }$ & & & \\
\hline & Zone of unsuitable work & $\sqrt{ }$ & $\sqrt{ }$ & $\sqrt{ }$ & & & \\
\hline \multirow{7}{*}{$\begin{array}{l}\frac{n}{0} \\
\frac{0}{2} \\
\sum_{i}^{0}\end{array}$} & $\begin{array}{l}\text { Calculation of the unpredictable } \\
\text { cost price }\end{array}$ & & & & $\sqrt{ }$ & $\sqrt{ }$ & \multirow{7}{*}{$\begin{array}{l}\text { Implementation of an information system; } \\
\text { Procedures. } \\
\text { Introduction of a multi-purpose agent "Water } \\
\text { spider" }\end{array}$} \\
\hline & Bad evacuation of parts & $\sqrt{ }$ & $\sqrt{ }$ & $\sqrt{ }$ & $\sqrt{ }$ & $\sqrt{ }$ & \\
\hline & Failing maintenance & & & & $\sqrt{ }$ & $\sqrt{ }$ & \\
\hline & $\begin{array}{l}\text { Bad organization arrangement of } \\
\text { tools }\end{array}$ & $\sqrt{ }$ & $\sqrt{ }$ & $\sqrt{ }$ & $\sqrt{ }$ & $\sqrt{ }$ & \\
\hline & No quality control & & & & $\sqrt{ }$ & $\sqrt{ }$ & \\
\hline & Stock shortage of raw materials & & & & $\sqrt{ }$ & $\sqrt{ }$ & \\
\hline & $\begin{array}{l}\text { Important rate of falls of raw mate- } \\
\text { rials }\end{array}$ & $\sqrt{ }$ & $\sqrt{ }$ & $\sqrt{ }$ & $\sqrt{ }$ & $\sqrt{ }$ & \\
\hline
\end{tabular}

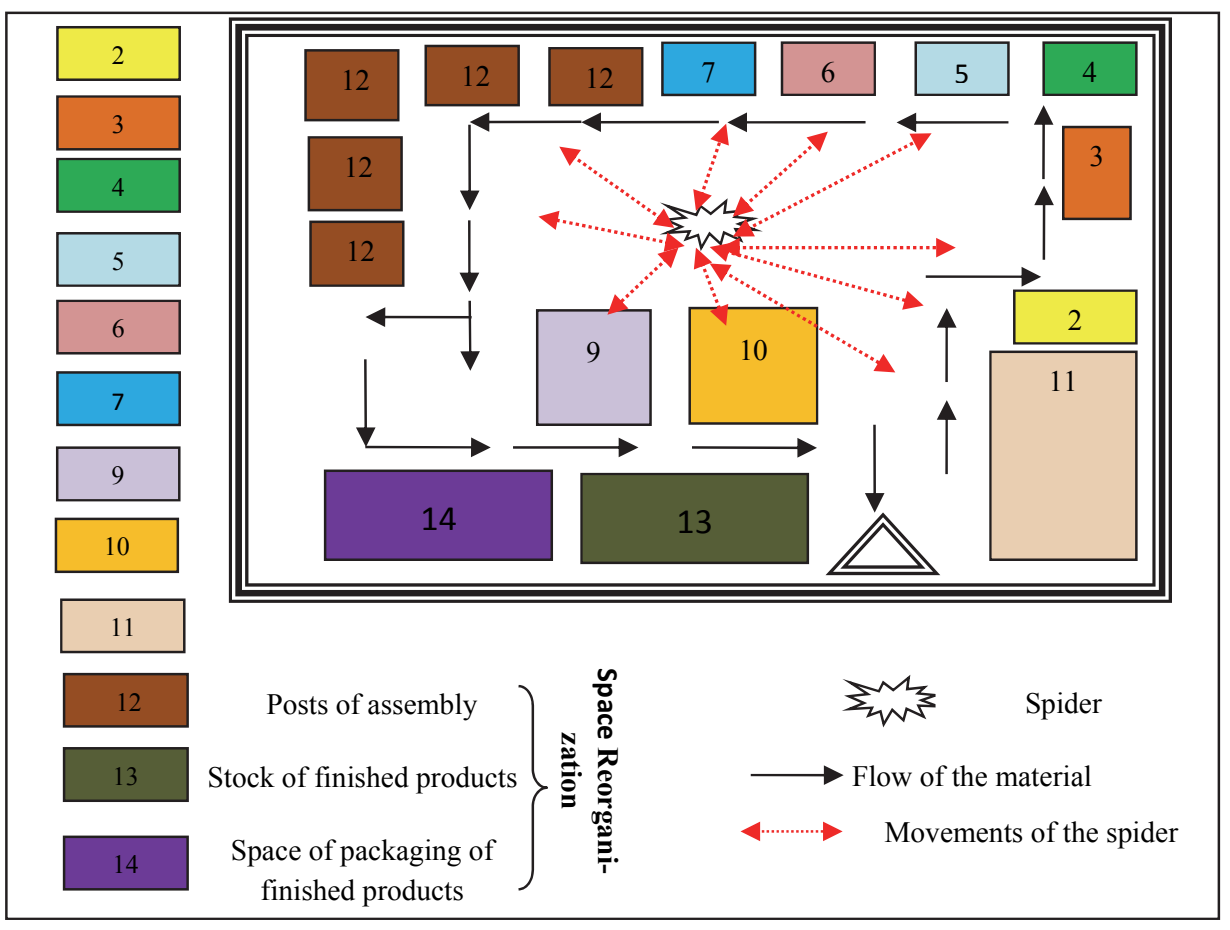

Fig.5. New organization of the workshop 
To reduce the numerous useless movements, we propose a physical and organizational reorganization of the workshop by the introduction of "the water spider" (Azzemou \& Noureddine, 2014) which is going to contribute to check and to regulate flows so allowing a better effective collaboration between all the members of the production team. It will lead to an optimization of the organizational, material and informative flows in Fig. 5.

\section{Synthesis and conclusion}

In this article, we proposed a model for the continuous improvement of the competitiveness of companies, integrating two iterative and sequential stages where we integrated the tools of Lean Manufacturing. Knowing that the best way of observing the process of production is to go on the ground, and in the context of the local industrial fabric, we implemented the model adopted on two Algerian firms by respecting their environment. At the end of the observations on the ground, we highlighted profits (Table 4) which ensue from it in the form of proposals of actions to be led. For the first company, the proposed solution strengthens the existing information system and allow so the implementation of a continuous improvement approach. The costs of storage are reduced by avoiding an overproduction and the transport number is returned to only one whatever the number of breakdowns. This proposal could be completed by the collection of all the information relative to the process of production to validate the solution. For the second firm, we proposed a reorganization of the factory to reduce the dimensions of the space and the frequent movements of the workers. By organizing jobs and name of a multi-purpose agent "Water spider" we eliminate the areas of wait. Indeed, this agent takes care of all the movements of the other workers.

Table 4

Results of the application of the model on both firms

\begin{tabular}{|c|c|c|c|c|c|}
\hline \multirow[b]{2}{*}{ Firm } & \multicolumn{2}{|c|}{ Approach Implementation } & \multicolumn{3}{|c|}{ Impact: Dimension } \\
\hline & Wasting & Solution & Economic & Social & Environmental \\
\hline $\begin{array}{l}\text { Public firm } \\
\text { of gas }\end{array}$ & $\begin{array}{l}\text { Overproduction } \\
\text { Useless operations }\end{array}$ & $\begin{array}{l}\text { Improvement of } \\
\text { the information } \\
\text { system }\end{array}$ & $\begin{array}{l}\text { Reduction of the } \\
\text { cost of storage } \\
\text { Reduction of the } \\
\text { transport }\end{array}$ & $\begin{array}{l}\text { Improvement of } \\
\text { the working con- } \\
\text { ditions }\end{array}$ & $\begin{array}{l}\text { Less } \\
\text { pollution }\end{array}$ \\
\hline $\begin{array}{l}\text { Private } \\
\text { SME }\end{array}$ & Useless movements & $\begin{array}{l}\text { Introduction of } \\
\text { a multi-purpose } \\
\text { agent } \\
\text { Refitting of the } \\
\text { workshop }\end{array}$ & $\begin{array}{l}\text { Improvement of } \\
\text { the productivity }\end{array}$ & $\begin{array}{l}\text { Facilitate the tasks } \\
\text { to the whole team } \\
\text { of the workshop. } \\
\text { Stability and secu- } \\
\text { rity of the working } \\
\text { environment. }\end{array}$ & $\begin{array}{l}\text { Less } \\
\text { pollution }\end{array}$ \\
\hline
\end{tabular}

The results obtained by the implementation of the model on these firms showed the impact of the introduced corrective actions, on three economic, social and environmental plans.

Indeed, the proposed approach allows the company to create well mastered and optimized processes, and to concentrate only on the value creation added to answer customer expectations in a fast, effective way and competitive costs. To quantify the economic impact of the practices Lean on the performance, a study of the costs in the process of production is before in progress and after the implementation of the model. The first results show an increase of the added value after the elimination of the wasting. On the other hand, grounds that the adopted model is based on the use of the tools of Lean Manufacturing, we envisage the integration of the other tools such as Kanban, Jidoka, SMED, Poka Yoke in the model to perpetuate the approach Lean. 


\section{References}

Azouaou, L. (2010). La politique de mise à niveau des PME algériennes : enlisement ou nouveau départ ?. Gème Colloque international, Hammamet (Tunisia).

Azzemou, R., \& Noureddine, M. (2012). Application of the 5S method in an Algerian firm. Management, 2 (5), 193-203.

Azzemou, R., \& Noureddine, M. (2014). Optimisation des flux de l'entreprise. In Actes de la 2ème Conférence francophone sur les Systèmes Collaboratifs SysCo'2014, Hammamet (Tunisia), 185198.

Bellon, B. (1991). La compétitivité. Traité d'Economie Industrielle. Economica.

Berger, T. (2008). Concepts of national competitiveness. Journal of International Business and Economy, 9(1), 91-111.

Chahal, V. \& Narwal, M.S. (2017). An empirical review of lean manufacturing and their strategies. Management Science Letters, 7(7), 321-336.

Dejardin, M. (2006). Compétitivité structurelle. Reflets et Perspectives de la vie économique, XLV(1), 5-13.

Demeter, K., \& Matyusz, Z. (2010). The impact of lean practices on inventory turnover. International Journal of Production Economics, 133(1), 154-163.

Gupta, S., \& Jain, S.K. (2013). A literature review of lean manufacturing. International Journal of Management Science and Engineering Management, 8 (4), 241-249.

Imai, M. (1997). Gemba Kaizen: A Commonsense, Low-Cost Approach to Management. McGraw-Hill.

Ishikawa, K. (1990). Introduction to quality control. Chapman \& Hall.

Ishikawa, K. (2007). La gestion de la qualité : Outils et applications pratiques. Dunod.

Jaca, C., Viles, E., Paipa-Galeano, L., Santos, J., \& Mateo, R. (2014). Learning 5S principles from Japanese best practitioners: case studies of five manufacturing companies. International Journal of Production Research, 52(15), 4574-4586.

Juran, J. (2004). Architect of quality. Mc Graw-Hill.

Kilpatrick, J. (2003). Lean Principles. Manufacturing Extension Partnership.

Kotler, P. \& Dubois, B. (2006). Marketing management. 12ème edition. Pearson Education.

Kumari, R., Quazi, T.Z., \& Kumar, R. (2015). Application of Lean Manufacturing Tools in Garment Industry. International Journal Of Mechanical Engineering And Information Technology, 3(1), 976982.

Lawrence, P., \& Lorsch, J. (1989). Adapter les structures de l'entreprise. Les Éditions d'Organisation.

Lyonnet, B. (2010). Amélioration de la performance industrielle : vers un système de production Lean adapté aux entreprises du pôle de compétitivité Arve Industries Haute-Savoie Mont-Blanc, Doctoral dissertation, Université de Savoie (France).

Marty, C. (1997). Le Juste à Temps : produire autrement. 2ème édition. Hermès.

Porter, M. (1998). The competitive advantage of nations. Mac Millan Press.

Real, R., Pralus, M., Pillet, M., \& Guizzi, L. 2007). Une première étape vers le Lean dans les entreprises de sous-traitance mécanique (Retour sur 7 ans de pratique). Actes de la 5ème Conférence Internationale Conception et Production Intégrées CPI'2007, Rabat (Morocco).

Shah, R., \& Ward, P.T. (2003) Lean manufacturing: context, practice bundles, and performance. Journal of Operations Management, 21(2), 129-149.

Sigh, B., \& Sharma, S.K. (2009). Value stream mapping as a versatile tool for lean implementation: an Indian case study of a manufacturing firm. Measuring Business Excellence, 13 (3), 58-68.

Trey, P. (2003). Le 5S, socle de l'efficacité industrielle: Mode d'emploi. Éditions AFNOR.

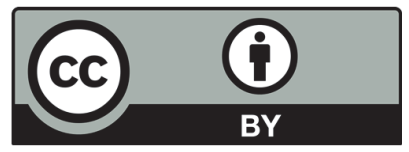

(C) 2018 by the authors; licensee Growing Science, Canada. This is an open access article distributed under the terms and conditions of the Creative Commons Attribution (CC-BY) license (http://creativecommons.org/licenses/by/4.0/). 